\title{
STEADY-STATE DIFFUSING CAPACITY DETERMINED BY A SIMPLIFIED METHOD
}

\author{
BY \\ G. L. LEATHART \\ From the Department of Industrial Health, the Medical School, King's College, University of \\ Durham, Newcastle, 1
}

One of the disadvantages of the method of Filley, MacIntosh, and Wright (1954) for determining the steady-state diffusing capacity is that it requires the collection and analysis of arterial blood. This adds materially to the time needed to make the determination. In normal individuals it is possible to use end-tidal $\mathrm{PCO}_{2}$ in place of arterial $\mathrm{PCO}_{2}$, or end-tidal concentration of $\mathrm{CO}$ as recommended by Bates, Boucot, and Dormer (1955). But in patients with abnormal distribution of pulmonary gases or blood-flow this method may be subject to error. For example, the endtidal $\mathrm{PCO}_{2}$ was $11 \mathrm{~mm}$. $\mathrm{Hg}$ lower than the arterial level in the 24 cases of respiratory disability studied by Hackney, Sears, and Collier (1958) and showed considerable scatter (S.D. $\pm 8.8 \mathrm{~mm}$. $\mathrm{Hg}$ ).

Hackney et al. (1958) described a quick and bloodless method for measuring the arterial $\mathrm{PCO}_{2}$ and this has been adapted for routine clinical use by Campbell and Howell (1960). A small volume of gas is rebreathed by the patient and eventually comes into equilibrium with the mixed venous blood returning to the lungs. It has been demonstrated that the tension of $\mathrm{CO}_{2}$ in this gas is $6 \mathrm{~mm}$. $\mathrm{Hg}$ more than in the arterial blood.

This paper describes 30 experiments in which the original method of Filley et al. (1954) is compared with a method in which the arterial $\mathrm{PCO}_{2}$ is measured by a rebreathing technique. The repeatability of the new method is then assessed.

The diffusing capacity of five patients was estimated in a similar way by Marshall (1958) but was not compared with the value obtained by a standard method.

\section{MethoD}

The subjects were 29 patients referred for assessment of respiratory function, the following diagnoses being represented: emphysema 11 cases (arterial $\mathrm{PCO}_{2}$ below $48 \mathrm{~mm}$. $\mathrm{Hg}$ in all), sarcoidosis 4 , asbestosis 4 , interstitial fibrosis 2 , anthracosis with progressive massive fibrosis 4 , and polycythaemia 2 .

All patients were examined while seated after a period of about 10 minutes' rest. The Filley method requires that the expired air and arterial blood should be collected simultaneously. But a rebreathed sample cannot be collected during the period of inhalation of $\mathrm{CO}$; instead it was collected immediately before the start of the inhalation of CO (sample A) and again 20 to 60 seconds after the end of $\mathrm{CO}$ inhalation (sample B). In some patients only one of these samples was taken.

Since inhalation of oxygen may alter the diffusing capacity for $\mathrm{CO}$, the rebreathing technique was not identical with that described by Campbell and Howell (1960). Expired air was collected in a small plastic bag of 2 litres capacity for two or three normal breaths and the patient then rebreathed this expired air for 15 seconds on three occasions separated by one minute. A fourth period of rebreathing took place either immediately before or immediately after the inhalation of $\mathrm{CO}$. It was shown that in a normal subject the concentration of $\mathrm{CO}_{2}$ in the bag became constant after three such rebreathings (occasionally after only two) and did not alter if the final period of rebreathing lasted up to 20 seconds. In patients 1 to 5 the method described by Campbell and Howell was used, but this was found to be less well tolerated by the breathless patient and to take slightly more time. A direct comparison of the two methods gave identical values for the mixed venous $\mathrm{CO}_{2}$ tension. Arterial and alveolar $\mathrm{PCO}_{2}$ were assumed to be $6 \mathrm{~mm}$. Hg less than the $\mathrm{PCO}_{2}$ of the rebreathed sample.

All patients breathed a mixture of $\mathrm{CO}$ in air through a mouthpiece and valve-box for six minutes. The strength of the mixture varied from $0.110 \%$ to $0.145 \% \mathrm{CO}$. Expired air was collected during the last three minutes and arterial blood was collected anaerobically during two of the last three minutes. Carbon monoxide was estimated by infra-red absorption; duplicate analyses never differed by more than $0.001 \%$. No allowance was made for $\mathrm{CO}_{2}$ because it was found that the deflection produced by $5 \%$ $\mathrm{CO}_{2}$ was equivalent to only $0.002 \% \mathrm{CO}$. Oxygen and carbon dioxide in expired air were estimated with the Haldane apparatus; the value accepted was the mean of duplicate analyses which were required to differ by no more than $0.1 \%$. The $\mathrm{CO}_{2}$ content of plasma was estimated with the Haldane blood-gas apparatus; the $p \mathrm{H}$ of whole blood was measured anaerobically with the electrode system recently 
described (Leathart, 1961) and $\mathrm{PCO}_{2}$ was computed from the nomograms of Peters and Van Slyke (1932).

When the repeatability of the method was being investigated, arterial $\mathrm{PCO}_{2}$ was estimated from a rebreathed sample collected immediately after the period of inhalation of CO (sample B). The subjects remained seated at rest for about 15 or 20 minutes between the two estimations. Duplicate estimations were made in 11 patients and five sets of duplicate determinations were completed in two normal subjects. These two subjects breathed the $\mathrm{CO}$ mixture for only 4 minutes and expired air was collected from them for only 2 minutes.

\section{RESULTS*}

The diffusing capacity of the lung $\left(D_{L}\right)$, estimated by the method of Filley et al. (1954) using arterial $\mathrm{PCO}_{2}$, is compared with the $\mathrm{D}_{\mathrm{L}}$ calculated from a rebreathed sample (Fig. 1). This figure records 30 determinations in 29 subjects. The mean difference betwen $D_{L}$ (direct $\mathrm{PCO}_{2}$ ) and $\mathrm{D}_{\mathrm{L}}$ (indirect $\mathrm{PCO}_{2}$ ) calculated from sample A ( 22 cases) was $-0.097 \mathrm{ml} . / \mathrm{min} . / \mathrm{mm}$. $\mathrm{Hg}$ (S.D. \pm 1.103$)$, while calculated from sample B (26 cases) it was $+0.026 \mathrm{ml} . / \mathrm{min} . / \mathrm{mm}$. $\mathrm{Hg}$ (S.D. \pm 1.062$)$. Occasional cases showed rather poor agreement between the two methods, especially if the differences were expressed as percentages of the $\mathrm{D}_{\mathrm{L}}$ (direct $\mathrm{PcO}_{2}$ ). Deviations then varied from as much as $+29 \%$ to $-25.6 \%$. In most cases, however, the difference was less

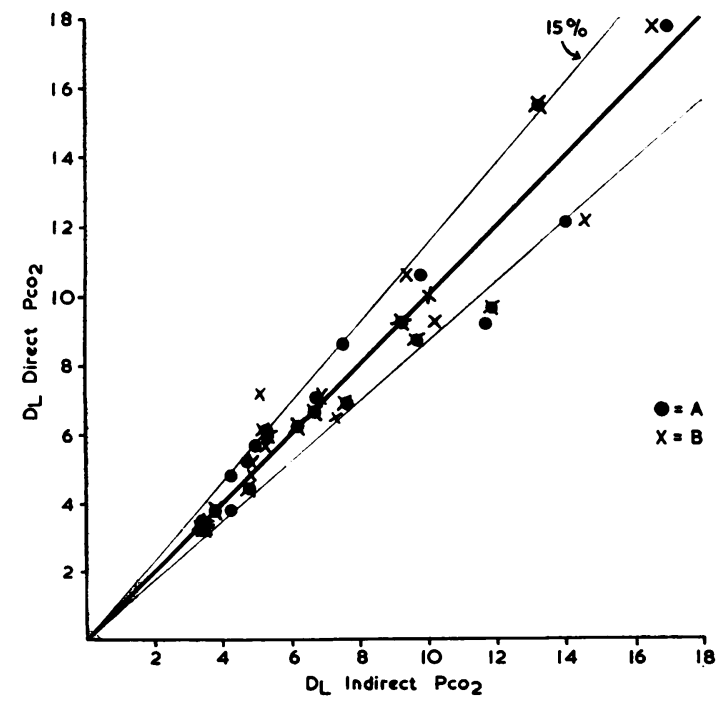

FIG. 1. $D_{\mathrm{L}}$ (direct $\left.\mathrm{PCO}_{2}\right)$ plotted against $D_{\mathrm{L}}$ (indirect $\mathrm{PCO}_{2}$ ). The units are $\mathrm{ml} . / \mathrm{min} . / \mathrm{mm}$. $\mathrm{Hg}$ standard temperaiure and pressure dry.

*Tables giving detailed results are available from the author. than $15 \%$, as shown in Fig. 1, and this can be considered satisfactory in view of the poor repeatability of the arterial method (Filley et al., 1954).

Repeatability.-Amongst the 11 patients the standard deviation of a single observation (calculated from the differences between duplicates) was $1.44 \mathrm{ml} . / \mathrm{min} . / \mathrm{mm}$. Hg. There was similar agreement between duplicates in one of the two normal subjects (S.D. \pm 1.54 ) but poor agreement in the other (S.D. \pm 2.65). The results are depicted in Figure 2.

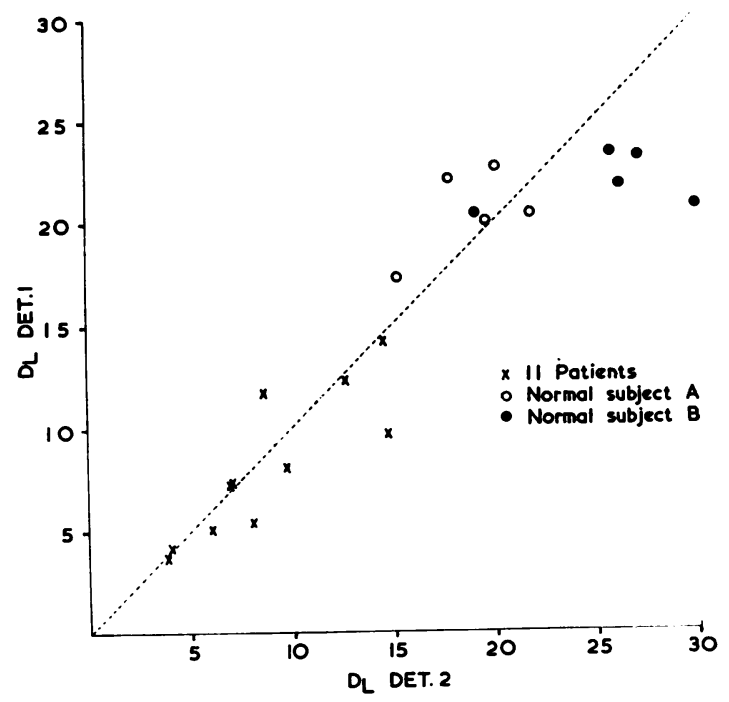

FIG. 2. Repeatability of $\mathrm{DL}_{\mathrm{L}}$ (indirect $\mathrm{PCO}_{2}$ ). First determination plotted against second determination made 15 to 20 minutes later (ml./min./mm. $\mathrm{Hg}$ ).

\section{Discussion}

There is only one reason why $\mathrm{D}_{\mathrm{L}}$ (direct $\mathrm{PCO}_{2}$ ) and $\mathrm{D}_{\mathrm{L}}$ (indirect $\mathrm{PCO}_{2}$ ) are not invariably identical. It is because the two methods give different values for the mean alveolar $\mathrm{PCO}_{2}$. The values differ for one or both of two reasons : either $\mathrm{PCO}_{2}$ alters during the interval between the collection of the two samples, or the methods of analysis are inaccurate. These two possibilities will be considered in more detail.

Alteration of the mean alveolar $\mathrm{PCO}_{2}$ during the interval between the two samples implies that the patient is not in a steady state, and the fault one sees most often is hyperventilation. This may, however, occur while the patient is getting accustomed to the apparatus and be followed by reactive hypoventilation during the collection of 
samples. Or the change may occur (in either direction) between the start and finish of the experimental period. These changes are difficult to detect, but if hyperventilation is present for the major part of the period of collection of expired air the respiratory quotient is found to be high. Such hyperventilation would cause a gradual fall of arterial and mean alveolar $\mathrm{PCO}_{2}$ during the experimental period, which lasts for six minutes, and one would therefore expect indirect determination $\mathbf{A}$ to give a higher value and indirect B a lower value to the arterial $\mathbf{P C O}_{2}$ than that obtained by collection of arterial blood during the fifth minute. By the same reasoning one would expect arterial blood analysis to agree more closely with "indirect B" than with "indirect A" because of the longer time interval between arterial sampling and the last of these two determinations. In practice, these expectations were seldom fulfilled; only one of the 13 cases with a respiratory quotient over 0.90 showed the expected differences between arterial and rebreathed values for $D_{L}$.

The failure of theoretical deduction to conform with the experimental findings cannot be ascribed to the fact that the rebreathing method measures mixed venous $\mathrm{PCO}_{2}$ rather than arterial. For, though the changes in mixed venous level are likely to be small, they should occur in the same direction as those assumed to occur in the alveoli. It therefore appears that the differences between $\mathbf{D}_{\mathbf{L}}$ (direct $\mathrm{PcO}_{2}$ ) and $\mathrm{D}_{\mathrm{L}}$ (indirect $\mathrm{PcO}_{2}$ ) are due to analytical errors, of which the most important may be the assumption that arterial $\mathrm{PCO}_{2}$ is always $6 \mathrm{~mm}$. $\mathrm{Hg}$ less than the mixed venous level.

This point was investigated in 60 patients by Hackney et al. (1958). They found that the rebreathing method overestimated the arterial $\mathrm{PCO}_{2}$ by $0.2 \mathrm{~mm}$. $\mathrm{Hg}$ with a standard deviation of $2.9 \mathrm{~mm}$. Hg, while Campbell and Howell (1960) found that it underestimated by $0.3 \mathrm{~mm}$. $\mathrm{Hg}$ with a standard deviation of $2.9 \mathrm{~mm}$. $\mathrm{Hg}$ (in 15 subjects). In the subjects described in this paper I have found that the rebreathing method (using sample B whenever possible) underestimated by $0.49 \mathrm{~mm}$. $\mathrm{Hg}$ with a standard deviation of 3.78 (maximum errors observed being +5.0 and -6.0 ), from which it appears that the presence of a pause between the collection of the arterial sample and of the rebreathed sample slightly increases the errors of this method of estimating arterial $\mathrm{PCO}_{2}$. The possibility that the rebreathing method may give an estimate of arterial $\mathrm{PCO}_{2}$ which differs from the arterial blood analysis by as much as $\pm 7.56 \mathrm{~mm}$. $\mathrm{Hg}$ is probably adequate to explain the differences between arterial and rebreathed values for diffusing capacity. It is, however, not clear which of these two methods of analysis gives the more accurate result.

The accuracy of direct estimation of arterial $\mathrm{PCO}_{2}$ is difficult to assess. The direct estimation of arterial $\mathrm{PCO}_{2}$ by the bubble equilibration technique used by Campbell and Howell (1960) is subject to an error of \pm 2 to $3 \mathrm{~mm}$. $\mathrm{Hg}$, while calculation shows that the indirect estimation of $\mathrm{PCO}_{2}$ from $\mathrm{CO}_{2}$ content and $\mathrm{pH}$, used by Hackney et al. (1958) and in the present paper, may err by \pm 2 to $4 \mathrm{~mm}$. $\mathrm{Hg}$ if the estimation of $\mathrm{CO}_{2}$ content is inaccurate by $\pm 1.0 \mathrm{ml} . / 100 \mathrm{ml}$. and $\mathrm{pH}$ errs by \pm 0.02 unit. Thus the probable error in the estimation of arterial $\mathrm{PCO}_{2}$ is approximately the same as the standard deviation of the difference between arterial $\mathrm{PCO}_{2}$ and rebreathed $\mathrm{PCO}_{2}$. It is therefore likely that about half of the difference between $\mathrm{D}_{\mathrm{L}}$ (direct $\mathbf{P C O}_{2}$ ) and $\mathrm{D}_{\mathrm{L}}$ (indirect $\mathrm{PCO}_{2}$ ) is attributable to inaccuracies in the determination of arterial $\mathrm{PCO}_{2}$ by the rebreathing method, while the other half is due to inaccuracies in the analysis of arterial blood.

Filley et al. (1954) realized that the steady-state method of estimating the diffusing capacity is subject to errors imposed by the limits of analytical accuracy and suggested that an error of $25 \%$ was possible. The size of the error depends on the accuracy with which dead-space effect can be calculated. It can be shown that variations in the dead-space effect have an increasingly great influence on the $D_{L}$ as the fractional uptake of $\mathrm{CO}$ increases. This is illustrated in Fig. 3 which demonstrates that the $D_{L}$ would be much more profoundly influenced by analytical errors in normal subjects than in patients with a depressed uptake of CO. Consequently the lower the $D_{\mathbf{L}}$ is found to be the more reliable is the finding. The reliability falls off as the fractional uptake increases, and this may account for the wideness of the limits of normality which previous workers have reported. If all the normal results recorded by Filley et al. (1954), by Ross, Frayser, and Hickam (1959), by Turino, Brandfonbrener, and Fishman (1959), and by Marks, Cugell, Cadigan, and Gaensler (1957), all of whom used Filley's method, are added together, the mean normal diffusing capacity of these 53 male subjects (aged 15 to 62 years) is $19.3 \mathrm{ml} . / \mathrm{min} . / \mathrm{mm}$. $\mathrm{Hg}$, with a standard deviation of 5.43 . When considered against this background the errors introduced by estimating the arterial $\mathrm{PCO}_{2}$ from a rebreathed sample collected after the inhalation of $\mathrm{CO}$ are small. Individual patients may be in error by as 


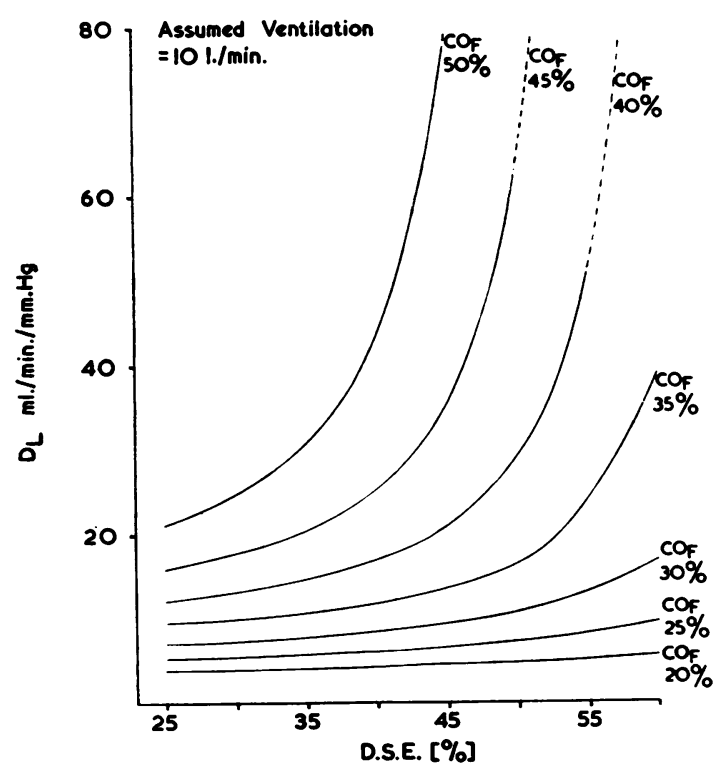

FIG. 3. Theoretical curves relating $D_{\mathrm{L}}$ and dead space effect $\left(\frac{V D}{V \Gamma} \times 100\right)$ at different values of fractional uptake of $\mathrm{CO}(\mathrm{CO})$.

much as $2.12 \mathrm{ml} . / \mathrm{min} . / \mathrm{mm}$. Hg. This may be important in border-line cases, but in most cases it is adequate to place them either within or below normal limits. It is therefore suggested that the indirect arterial $\mathrm{PCO}_{2}$ gives an estimate of the steady-state diffusing capacity which is sufficiently accurate for most uses and that the analysis of arterial blood should be reserved for those borderline cases in which particular importance is attached to the result. The elimination of blood analysis saves a great deal of time and a determination can be completed in about 15 minutes. Thus it is quite feasible to repeat the test after a short interval.

RePEatability. - The differences between repeated determinations which were found in the present work (S.D. $\pm 1.44 \mathrm{ml} . / \mathrm{min} . / \mathrm{mm}$. $\mathrm{Hg}$ ) were similar to those reported previously. Holland and Blacket (1958) used Filley's method and reported a standard deviation between duplicates of 2.4 $\mathrm{ml} . / \mathrm{min} . / \mathrm{mm}$. $\mathrm{Hg}$ in normal subjects. Bates et al. (1955), using end-tidal samples, recorded a standard deviation of $2.5 \mathrm{ml} . / \mathrm{min} . / \mathrm{mm}$. $\mathrm{Hg}$, while MacNamara, Prime, and Sinclair (1959), using Bates' method, found it to be \pm 3.26 in normal subjects at rest, \pm 1.45 in patients with emphysema, and \pm 1.57 in those with diffuse fibrosis of the lungs.
It appears, therefore, that the method described in this paper gives results which are no less repeatable than those obtained by other methods. Nevertheless there is often a large difference between duplicate results, especially in normal subjects, and especially when the differences are expressed as a fraction of the average of the two determinations (range $+41 \%$ to $-29 \%$ ). Possible reasons for these discrepancies are discussed below.

Differences between repeated determinations of a human characteristic may be due to biological variation or to analytical errors, and it is not easy to assess the relative importance of these two. This is especially so in the estimation of the diffusing capacity of normal subjects, in whom small errors of analysis lead to large differences in the determination (as illustrated in Fig. 3), and in whom the diffusing capacity does not have the constancy which is characteristic of disease (Bates, Knott, and Christie, 1956). It is known that diffusing capacity increases with exertion and it has been shown to be proportional to oxygen uptake in children. While it is certain that it does not increase as much as oxygen uptake during violent exercise, it is possible to make an allowance for differences in metabolic rate at rest by calculating the $D_{L}$ per unit of oxygen absorbed. This was found to be almost identical in the two determinations in six instances, and it is probable that true biological variation accounts for the difference between the duplicate results in these cases.

Although it has been shown that $D_{L}$ alters when the resting volume of the lung changes and with violent hyperventilation (Turino et al., 1959 ; Ross et al., 1959), it is not considered likely that this can explain why the repeatability is so poor in the other cases. It is more likely that the explanation lies in failure to maintain a steady state. In this context a "steady state" is one in which the arterial $\mathrm{PCO}_{2}$ does not alter during the collection of the expired air sample.

Analysis of arterial blood before and after collection of expired air would establish whether or not a steady state had been attained, but this analysis has not been done. However, the mixed venous $\mathrm{PCO}_{2}$ has been determined in 75 patients with various pulmonary diseases before and after the inhalation of $\mathrm{CO}$ (i.e., on two occasions separated by about seven minutes). The mean difference between the two estimations was found to be $0.196 \mathrm{~mm}$. $\mathrm{Hg}$, with a standard deviation of $1.780 \mathrm{~mm}$. $\mathrm{Hg}$, and in the subjects described in this paper the mixed venous $\mathrm{PCO}_{2}$ 

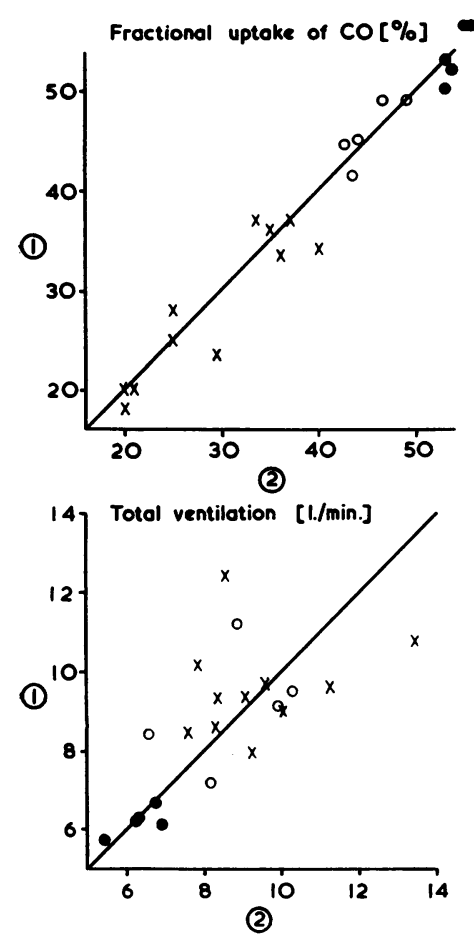

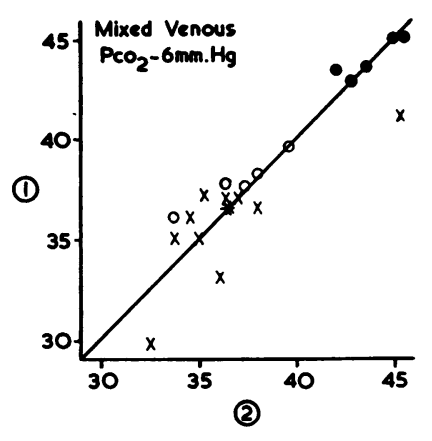

FIG. 4. Repeatability of the four factors involved in the calculation of $D_{\mathrm{L}}$ (indirect $\mathrm{PCO}_{2}$ ): (1) and (2) refer to first and second determinations: $\mathrm{X}=$ patients $; \mathrm{O}=$ subject $A ; \bullet=$ subject $B$.

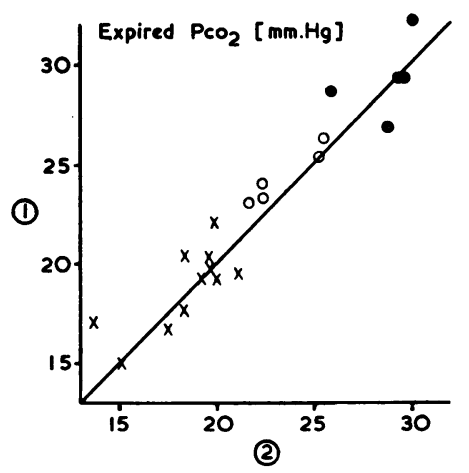

was almost the same on two occasions separated by 15 to 25 minutes (mean difference $0.329 \mathrm{~mm}$. Hg, S.D. $\pm 1.697 \mathrm{~mm}$. Hg). However, the relative constancy of the mixed venous $\mathrm{PCO}_{2}$ does not mean that the arterial $\mathrm{PCO}_{2}$ also was constant. For arterial $\mathrm{PCO}_{2}$ is known to be labile, especially in normal subjects, while mixed venous $\mathrm{PCO}_{2}$ is fairly stable. The stability of mixed venous $\mathrm{PCO}_{2}$ is shown in Fig. 4 which also demonstrates that total ventilation varied more between the two determinations than any of the other three factors which enter into the calculation of $D_{L}$. Though an altered minute volume does not necessarily imply that the subjects were not in a steady state on each occasion or that arterial $\mathrm{PCO}_{2}$ was different on the two occasions, it certainly suggests these two conditions. It is the slow response of mixed venous $\mathrm{PCO}_{2}$ to changes in alveolar ventilation which reduces the repeatability and lowers the accuracy of the determination of steady-state $D_{\mathbf{L}}$ by the simple method described in this paper.

It will be noticed that the duplicate analyses for subject B (Fig. 4, dark circles) showed less variation than those for other subjects (except perhaps in mixed expired $\mathrm{PCO}_{2}$ ) although this subject showed the greatest differences between duplicate determinations of $\mathbf{D}_{L}$. This demonstrates how small alterations in the four factors have a great effect on $D_{L}$ in the normal subject and also suggests, since mixed expired $\mathrm{PCO}_{2}$ was more variable than total ventilation, that spontaneous alterations in tidal volume may be an important cause of failure to maintain a steady state or of discrepancy between arterial $\mathrm{PCO}_{2}$ and mixed venous $\mathrm{PCO}_{2}$ less $6 \mathrm{~mm}$. $\mathrm{Hg}$.

It is concluded that the use of an indirect arterial $\mathrm{PCO}_{2}$ does not give good agreement between repeated observations of diffusing capacity in normal individuals, but when the diffusing capacity is low the agreement improves. The modification of the method of Filley et al. (1954), which is proposed in this paper, makes it easy to repeat observations and gives results which, in patients with diseased lungs, do not differ from those obtained by the slower method originally described. The results are, however, likely to be less accurate in normal individuals.

\section{SUMMARY}

The steady-state diffusing capacity of the lungs was measured by the method of Filley et al. (1954) in 29 patients with pulmonary disease. The effect of using a rebreathing technique for the determination of arterial $\mathrm{PCO}_{2}$ was investigated. 
It was shown that the use of an indirect arterial $\mathrm{PCO}_{2}$ gave results similar to those obtained by arterial blood analysis, especially in the more abnormal patients. Most of the results obtained by the rebreathing method fell within $15 \%$ of those obtained by arterial analysis.

The repeatability of the results obtained when using indirect arterial $\mathrm{PCO}_{2}$ was studied in 11 patients and was found to be similar to that reported for the methods which use arterial blood analysis or end-tidal sampling.

There was less agreement between duplicate results in two normal subjects because the calculation is very sensitive to alterations in the ratio VD/VT when the fractional uptake of $\mathrm{CO}$ is high.

The delay in the response of mixed venous $\mathrm{PCO}_{2}$ to spontaneous alterations in alveolar ventilation (mainly caused by alterations in tidal volume) is the probable cause of the failure to obtain more accurate agreement between duplicate determinations.

Despite these reservations it is suggested that indirect arterial $\mathrm{PCO}_{2}$ can be used in the calculation of diffusing capacity and gives results which are acceptable for most clinical purposes. The ease of performance of this modification outweighs its greater degree of inaccuracy.

\section{REFERENCES}

Bates, D. V., Boucot, Nancy G., and Dormer, A. E. (1955). J. Physiol. (Lond.), 129, 237.

Knott, J. M. S., and Christie, R. V. (1956). Quart. J. Med., N.S. 25, 137.

and Pearce, J. F. (1956). J. Physiol. (Lond.), 132, 232.

Campbell, E. J. M., and Howell, J. B. L. (1960). Brit. med. J., 1, 458.

Filley, G. F., MacIntosh, D. J., and Wright, G. W. (1954). J. clin. Invest, $33,530$.

Hackney, J. D., Sears, C. H., and Collier, C. R. (1958). J. appl. Physiol., 12, 425.

Holland, R. A. B., and Blacket, R. B. (1958). Aust. Ann. Med., 7, 192.

Leathart, G. L. (1961). Lancet, 1, 88.

MacNamara, J., Prime, F. J., and Sinclair, J. D. (1959). Thorax, $14,166$.

Marks, A., Cugell, D. W., Cadigan, J. B., and Gaensler, E. A. (1957). Amer. J. Med., 22, 51.

Marshall, R. (1958). J. clin. Invest., 37, 394.

Peters, J. P., and Van Slyke, D. D. (1932). Quantitative Clinical Chemistry, vol. 2, p. 294. Bailli- re, Tindall and Cox, London.

Ross, J. C., Frayser, Regina, and Hickam, J. B. (1959). J. clin. Invest., 38, 916.

Turino, G. M., Brandfonbrener, M., and Fishman, A. P. (1959). Ibid., 38, 1186. 